\title{
Research on Route Optimization of Sino-Europe Container Sea-rail Transport
}

\author{
Changqi Ji", a, Zuoyi Liü,b \\ 1,2School of Traffic and Transportation, Beijing Jiaotong University, Beijing 100044, China \\ a847516394@qq.com, bzyliu@bjtu.edu.cn
}

\begin{abstract}
Keywords: Container sea-rail transport, Route optimization, Time-cost model, Multi-objective ACO Abstract. The paper summarizes domestic and foreign researches about route optimization of multimodal transport. On this base, it first analysis the operational modes and influential factors for container sea-rail transport. Next, it puts China and Europe as the endpoints of route and analysis the alternative route from sea, rail and road these three kinds of transport. Then it builds time-cost model for container sea-rail transport. Wherein, the minimum total transport time and cost are both as objective function. In order to solve the double-objective route optimization model, the paper designs a multi-objective ant colony algorithm which accord with network characteristics of route with MATLAB. It also takes contradictions among the different sub-objectives into account and puts Pareto optimal solution set in it. Finally, it discusses a case study about the model.
\end{abstract}

\section{Introduction}

Most of the traditional transportation accomplished the port-to-port transport by sea. However, with the development of society, the door-to-door transport becomes one of the trends in the future and the multimodal transport emerges as the times require. Compared with other intermodal transport, sea-rail transport has some advantages in the aspects of safety, reliability, punctuality, energy saving, environmental protection and so on. According to the data of carbon emission of per unit of conversion volume of turnover, the figure of water transport is the least, then is railway transport, road transport and air transport emit more carbon dioxide than the above modes of transport. Considering these, sea-rail transport is worth to develop. But in our country, the average proportion of sea-rail transport in the port is only about $2 \%$. It is far below that of the large container ports in the foreign which is $15 \%$ to $30 \%$. This left a huge space for our country to develop container sea-rail transport. Besides, with the proposing of the belt and road strategy and the development of trade between China and Europe, it is essential to choose a suitable route to transport between them.

The earliest multimodal transport path optimization model was proposed by American scholar Reddy [1] in 1995, which the objective function of model is the total cost. Ziliaskopoulos et al. [2] consider the influence of time factor on the intermodal transport network and establish the model with total time as the goal. Lozano A et al. [3] use the Label method to search the shortest path in the intermodal network and put the transport cost and the number of transitions between different modes of transport as objective function. Sathapom Opasanon et al. [4] research the stochastic network which changes with time and use a path search method to observe changes of transit time. Milan Janie [5] discusses internal and external costs in multimodal transport and puts the least costs of both as goal. T-S Chang [6] formulates the international intermodal routing problem to a multiobjective multimodal multicommodity flow problem (MMMFP) with time windows and concave costs, then builds the model with the relaxation constraint and decomposition method. Jae et al. [7] present a Weighted Constrained Shortest Path Problem (WCSPP) model and apply Pareto optimal solution and the Label Setting algorithm to deal with it. H. Ayed et al. [8] take the impact of traffic congestion into account and propose a hybrid algorithm that combines Dijkstra and ant colony algorithm.

Based on the past researches, this paper first considers influential factors of container sea-rail transport between China and Europe, then builds time-cost model for it. Finally, it applies multi-objective ant colony algorithm solve an instance and take the conclusions. 


\section{Background}

The operational modes of sea-rail transport in China are mainly two kinds that are water-rail mode and water-road-rail mode. For route selection of container sea-rail transport, it is affected by a number of factors and some of them are mutual restraints. Wherein, they can be divided into nine main factors, namely, transport distance, cost, time, quality, cargo safety, transshipment in note, cargo clearance, infrastructures and transport facilities, capacity of traffic network and transshipment in city node and cargo properties. For route selection of container sea-rail transport between China and Europe, the maritime transport routes mainly relies on the traditional Sino-Europe lines, while the land transport channel are mainly based on Asian Highway Network and Trans-Asian Railway Network which connect and play a key role on two continents.

\section{Model}

\section{Problem description and construction of through traffic network}

There is a batch of goods that needs to be transported from origin $O$ to destination $D$. Meantime, $O$ and $D$ are in different countries and have $n$ transit points en route. There are one or more modes of transport between any two transit nodes. The shipper will be able to determine whether to change the transport mode or not or change to what mode of transport at any joint terminals of transshipment by their own requirements. This will make the calculation of final cost and time has a certain difference. Besides, it will also be limited by the maximum capacity among all lines and the allowed number of goods transshipment in the whole process of transport.

In order to show the process of sea-rail transport clearly, it has established a simple network map. There are $n$ nodes, $m$ arcs in the graph $G\left(V_{n}, E_{m}\right)$ and arc $(i, j)$ can use one to three kinds of transport among waterway, railway and highway. Nodes can be split according to all possible transport modes to make the network more clearly. Then the increased nodes are arranged in column to indicate that they are in the same stage and can not be passed in any routes simultaneously. So it can reflect the situation of transshipment among the nodes better. It is shown in Fig. 1.

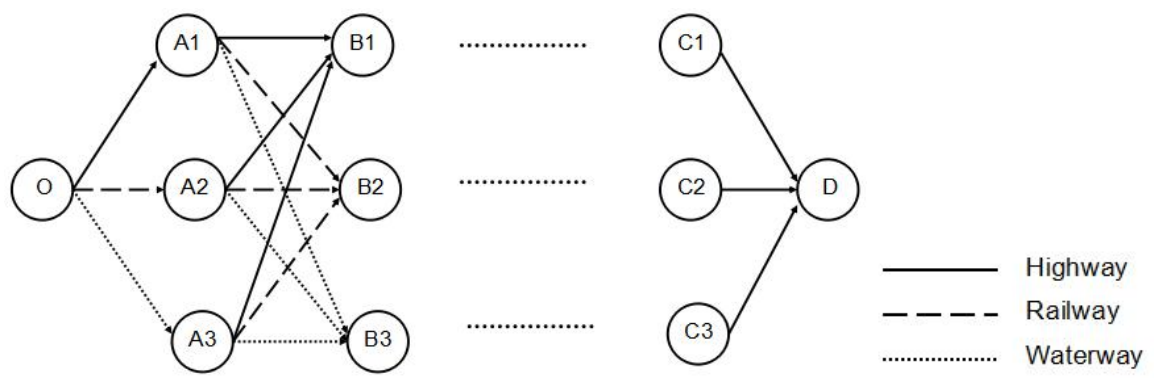

Fig. 1 Graph of splitting notes

\section{Hypothesis of model}

1) As the container transport needs the corresponding loading and unloading machines to complete the transshipment process, so transit transport always occurs in the corresponding joint nodes. In the model, the connection among the different modes of transport is only allowed at the nodes and other conditions need to meet the requirements of transshipment.

2) The sea-rail transport is taken place among $n$ cities and each city is treated as a node.

3) The sea-rail transport chooses containers as the mean of transport, and they are all handled in full container load. There are at most three kinds of optional means of transport between the two nodes that are waterway, railway and highway. Waterway includes maritime and inland water transport.

4) The volume of traffic can not be split, namely, there is only one mode and route of transport between two nodes.

5) It considers different discount rates due to different volume of traffic.

6) Do not consider the limits of transport capacity. 


\section{Objective function and constraint condition}

The objective function is the minimum total cost and time of transport. Wherein, total transport time is consisted of four parts, namely, transport time, transit time, customs clearance time and waiting time. The total transport cost includes three parts, namely, transport costs, transit costs and cargo damage costs. Due to customs clearance costs and waiting costs are uncertain, no uniform standards and share small proportion, this paper ignores them. The model is as follows:

$$
\begin{aligned}
& \min Z_{1}=\sum_{i \in I} \sum_{k \in J} c_{i, i+1}^{k} x_{i, i+1}^{k}\left(1-\theta_{q}^{k}\right)+\sum_{i \in I} \sum_{k \in J} \sum_{l \in J} h_{i}^{k l} y_{i}^{k l}+\sum_{i \in I} \sum_{k \in J} \sum_{l \in J} L_{i}^{k l} v \\
& \min Z_{2}=\sum_{i \in I} \sum_{k \in J} t_{i, i+1}^{k} x_{i, i+1}^{k}+\sum_{i \in I} \sum_{k \in J} \sum_{l \in J} a_{i}^{k l} y_{i}^{k l}+\sum_{i \in I} \sum_{k, l \in J} b_{i, i+1} g_{i, i+1}+\sum_{i \in I} \sum_{k \in J} \sum_{l \in J} w_{i} y_{i}^{k l} \\
& \sum_{k \in J} x_{i, i+1}^{k}=1 \quad \forall i \in I, \forall k \in J \\
& \sum_{k \in J} \sum_{l \in J} y_{i}^{k l} \leq 1 \quad \forall i \in I, \forall k, l \in J \\
& \sum_{k, l \in J} g_{i, i+1} \leq 1 \quad \forall i \in I, \forall k, l \in J \\
& x_{i-1, i}^{k}+x_{i, i+1}^{k} \geq 2 y_{i}^{k l} \quad \forall i \in I, \forall k, l \in J \\
& x_{i, i+1}^{k}, y_{i}^{k l}, g_{i, i+1} \in\{0,1\} \quad \forall i \in I, \forall k, l \in J
\end{aligned}
$$

Objective function:

Eq. 1 is the minimum total transport costs, wherein, $\sum_{i \in I} \sum_{k \in J} c_{i, i+1}^{k} x_{i, i+1}^{k}\left(1-\theta_{q}^{k}\right)$ is transport cost; $\sum_{i \in I} \sum_{k \in J} \sum_{l \in J} h_{i}^{k l} y_{i}^{k l}$ is transit cost; $\sum_{i \in I} \sum_{k \in J} \sum_{l \in J} L_{i}^{k l} v$ is cargo damage cost.

Eq. 2 is the minimum total transport time, wherein, $\sum_{i \in I} \sum_{k \in J} t_{i, i+1}^{k} x_{i, i+1}^{k}$ is transport time; $\sum_{i \in I} \sum_{k \in J} \sum_{l \in J} a_{i}^{k l} y_{i}^{k l}$ is transit time; $\sum_{i \in I} \sum_{k, l \in J} b_{i, i+1} g_{i, i+1}$ is customs clearance time; $\sum_{i \in I} \sum_{k \in J} \sum_{l \in J} w_{i} y_{i}^{k l}$ is waiting time.

Constraint condition:

Eq. 3 indicates that each pair of cities is only allowed to choose one mode of transport, which is the volume of traffic can not be divided.

Eq. 4 indicates that it is allowed only once operation of transshipment in any city $i$.

Eq. 5 indicates that there is at most once operation of customs clearance between any pair of cities.

Eq. 6 indicates that it is to ensure continuity of transport.

Eq. 7 indicates that the value of decision variables is 0 or 1 which is integer.

\section{Decision variables and definitions of related parameters}

$x_{i, i+1}^{k}= \begin{cases}1 & \text { choose mode of transport } k \text { between city } i \text { and city } i+1 \\ 0 & \text { otherwise }\end{cases}$

$y_{j}^{k l}= \begin{cases}1 & \text { need to transshipment in city } i \text { and change mode of transport } k \text { to mode of transport } l \\ 0 & \text { no need to transshipment }\end{cases}$

$g_{i, i+1}= \begin{cases}1 & \text { complete operation of customs clearance between city } i \text { and city } i+1 \\ 0 & \text { no need to customs clearance }\end{cases}$

$c_{i, i+1}^{k}$ - unit transport cost for choosing mode of transport $k$ from city $i$ to city $i+1$

$h_{i}^{k l}$ - unit transit cost for transshipment from mode of transport $k$ to $l$ in the city $i$

$t_{i, i+1}^{k}$ - transport time for choosing mode of transport $k$ from city $i$ to city $i+1$ 
$a_{i}^{k l}$ - transit time for transshipment from mode of transport $k$ to $l$ in the city $i$

$b_{i, i+1}$ - customs clearance time from city $i$ to city $i+1$

$L_{i}^{k l}$ - cargo damage rate for transshipment from mode of transport $k$ to $l$ in the city $i$

$v$ - unit value of cargo

$w_{i}$-waiting time in the city $i$

$\theta_{q}^{k}$-discount rate of freight in the volume of traffic $q$ by mode of transport $k$

$r_{i}^{k}$-fixed departure time from city $i$ by mode of transport $k$ (here refers to regular trains or liners), if there is no regular rains or liners at this nodes, or there is road transport which can depart at any time,so $r_{i}^{k}=0$

$p_{i}$ - actual arrival time of cargo for city $i$

$w_{i}= \begin{cases}0 & \text { if choosing road transport which can depart at any time without fi xed departure time } \\ r_{i}^{k}-p_{i} & \begin{array}{ll}\text { if choosing other modes of transpor } \mathrm{t} \text { expect road transport and there is no t ransit } \\ \text { transport in it }\end{array} \\ r_{i}^{k}-p_{i}-a_{i}^{k l} & \text { if choosing other modes of transport expect road transport and there is trans it transport } \\ & \text { from mode of transport } k \text { to } l\end{cases}$

$I$ - set of transport nodes

$J$ - set of mode of transport

$Z_{1}$ - total transport costs

$Z_{2}$ - total transport time

\section{Solution and Case Study}

\section{Overview of model solving methods}

This paper is a multi-objective optimization problem in which the objective functions of time and cost are contrary. The optimization of one sub- objective performance usually results in deterioration of the other sub-objective performance. In order to balance each sub-objective under the model framework, it is necessary to obtain a number of noncritical solutions that is the Pareto optimal solution. Finally, we choose the multi-objective ant colony algorithm which matches with characteristics of route network in MATLAB to solve the case.

\section{Instance simulation for route optimization of Sino-Europe container sea-rail transport}

Case description: a Chinese transport company undertakes a transport task of a batch of goods which requires it to be transported from Germany to China with the traffic volume of 1200 tons, about 100 TEU. The total value of the goods is estimated at around 6 million dollars which is high value container goods. For routes of goods traffic, we mainly consider the routes of sea-rail transport. Wherein, routes of land transport need to pass through Central Asia or Russia. In this case, because there is running many regular trains between China and Europe, the land transport can consider mainly using railways, rather the maritime routes are based on the traditional European lines which also involve the inland water transport in China, and the rest of traffic sections are mainly road transport. In this case, the goods need to be transported from Germany to China and selected city nodes are shown in Table 1:

Table 1 Label of city nodes

\begin{tabular}{cccccc}
\hline $\begin{array}{c}\text { Label } \\
\text { City }\end{array}$ & A & B & C & D & E \\
Label & F & Duisburg & Hamburg & Bremen & Rotterdam \\
City & Antwerp & Chongqing & Zhengzhou & Wuhan & Shanghai \\
\hline
\end{tabular}


According to the different ways to split the node, it can get the following network diagram of through traffic:
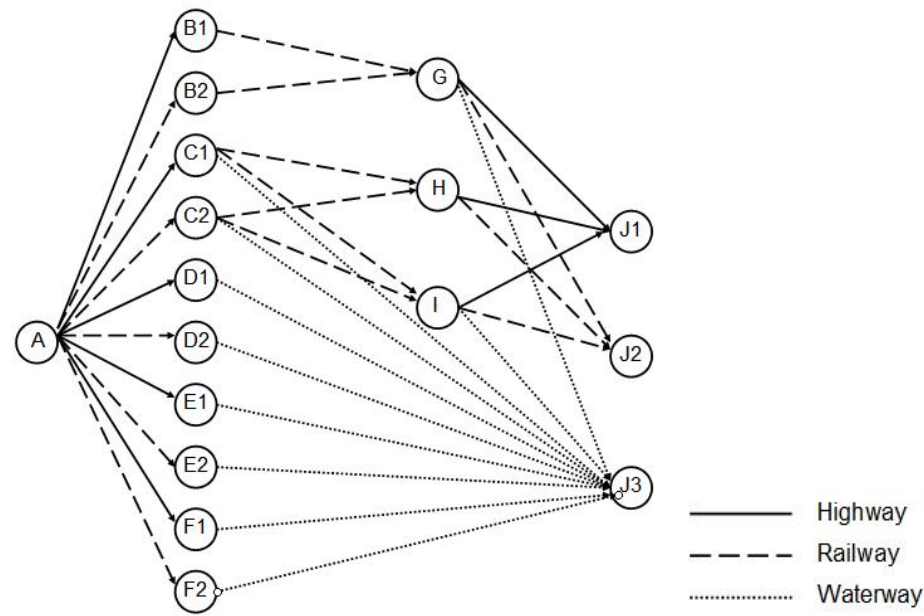

Fig. 2 Through traffic diagram of case

Among them, there are three routes for regular trains between China to Europe that are Duisburg to Chongqing (Chongqing-Sinkiang-Europe), Hamburg to Zhengzhou (Zhengzhou-Europe) and Hamburg to Wuhan (Wuhan-Europe). These regular trains pass through China, Central Asia and Russia to Europe. In the case, it only considers origin and destination of regular trains in three lines as nodes and the cities in the middle of lines are not viewed as transport nodes. But the customs clearance and problem of transshipment among different countries should be taken into account.

The basic data is as followed. Table 2, 3 shows the transport distance and price data between each pair of cities or ports in the case. Table 4 is transport costs and running frequency for China- Europe regular trains.

Table 2 Distance and traffic price of highway and railway between cities

\begin{tabular}{|c|c|c|c|}
\hline No. & Pair of cities & Highway [kilometer] & Railway [kilometer] \\
\hline 1 & Berlin-Duisburg & 542 & 520 \\
\hline 2 & Berlin-Hamburg & 283.74 & 311.11 \\
\hline 3 & Berlin-Bremen & 442.38 & 451.11 \\
\hline 4 & Berlin-Rotterdam & 716.08 & 741.10 \\
\hline 5 & Berlin-Antwerp & 812.73 & 844.43 \\
\hline 6 & Duisburg-Chongqing & - & 11000 \\
\hline 7 & Hamburg-Zhengzhou & -- & 10214 \\
\hline 8 & Hamburg-Wuhan & - & 10700 \\
\hline 9 & Chongqing-Shanghai & 2150 & 2516 \\
\hline 10 & Zhengzhou-Shanghai & 1095 & 998 \\
\hline 11 & Wuhan-Shanghai & 919 & 1403 \\
\hline Transport unit price & China & 10 & 3.5 \\
\cline { 2 - 4 } [yuan/TEU. kilometer] & Europe & 16 & 5 \\
\hline
\end{tabular}

Table 3 Distance and traffic price between ports

\begin{tabular}{|c|c|c|c|}
\hline \multirow{2}{*}{ No. } & Pair of ports & line distance [nautical miles] & $\begin{array}{c}\text { USD/TEU(Europe) or } \\
\text { RMB/TEU (Yangtze River) }\end{array}$ \\
\hline 1 & Hamburg-Shanghai & 10778 & 760 \\
\hline 2 & Bremen-Shanghai & 10730 & 825 \\
\hline 3 & Rotterdam-Shanghai & 10525 & 760 \\
\hline 4 & Antwerp-Shanghai & 10530 & 750 \\
\hline 5 & Chongqing-Shanghai & 2399 & 2500 \\
\hline 6 & Wuhan-Shanghai & 1125 & 1300 \\
\hline
\end{tabular}

Besides, the transshipment costs in different transshipment place are not same. In the railway station, it takes 150 yuan/TEU. In the port terminal, sea transport takes 370 yuan/TEU and water transport of Yangtze River takes 240 yuan/TEU. Meantime, the paper sets the maximum cargo 
damage rate within $0.5 \%$ according to the requirements of commodity transport quota loss and considers the difference in different transit methods.

Table 4 Transport costs and running frequency for China - Europe regular trains

\begin{tabular}{|c|c|c|c|}
\hline Name of regular trains & $\begin{array}{c}\text { Transport cost } \\
\text { [dollars] }\end{array}$ & $\begin{array}{c}\text { Transport cost } \\
\text { [yuan] }\end{array}$ & $\begin{array}{c}\text { Running frequency } \\
\text { [trains/week] }\end{array}$ \\
\hline Chongqing-Sinkiang-Europe & 8900 & 57616.82 & $3-4$ \\
\hline Zhengzhou-Europe & 10500 & 67974.90 & 2 \\
\hline Wuhan-Europe & 12000 & 77685.60 & 1 \\
\hline
\end{tabular}

For transport time, assuming that transport in this case is at uniform speed. Wherein, the average speed of road container transport is $80 \mathrm{~km} /$ hour and that of railway container transport is $60 \mathrm{~km} /$ hour. Due to the regular trains between China and Europe pass across a number of countries with different conditions of railway and have the phenomenon of fast at ends and slow in the middle of routes, so it can set the average running speed of railway at $50 \mathrm{~km} /$ hour. The speed of ship in the sea can take 24 knot and ship in the Yangtze River can take 12 knot according to speed limit on different parts. And it can be assumed that the efficiency of transshipment operation at the railroad station is $63.57 \mathrm{~min} / 100 \mathrm{TEU}$ [9] and that of port terminal is $140 \mathrm{~min} / 100 \mathrm{TEU}$ [10]. In this case, it considers that it is free from customs clearance among member states of EU and not calculate the corresponding customs clearance time. The customs clearance time for the rest regions chooses the optimal situation to calculate which takes 12 hours. The waiting time in this case is only considered the waiting time caused by departure of regular trains according to the timetable.

\section{Result analysis}

In order to simulate the instance, the paper programs multi-objective ant colony algorithm with MATLAB. First, it splits nodes according to the above principles and numbers them. Then it solves the instance by steps of ant colony algorithm. Wherein, the relevant parameters of algorithm are set as follows: the iterative number of ant colony is 80 , the number of ants is 20 , information heuristic factor is 5 , expected heuristic factor is 1 , retention rate of pheromone is 0.5 , intensity of pheromone is 3 .

After 80 iterations, the algorithm basically converges. It can get a group of Pareto optimal solution set. Restoring the results to the actual city node, it is shown in the following Table 5:

Table 5 Pareto optimal solution set

\begin{tabular}{|c|c|c|c|}
\hline No & Viable route & $\begin{array}{l}\text { Total transport cost } \\
\text { [yuan] }\end{array}$ & $\begin{array}{l}\text { Total transport time } \\
\text { [hour] }\end{array}$ \\
\hline 1 & $\begin{array}{l}\mathrm{A} \rightarrow \mathrm{C} 2 \rightarrow \mathrm{H} \rightarrow \mathrm{J} 1 \\
\text { Berlin(railway)Hamburg(railway) Zhengzhou(highway) Shanghai }\end{array}$ & 1499479.7 & 296.34 \\
\hline 2 & $\begin{array}{c}\mathrm{A} \rightarrow \mathrm{C} 2 \rightarrow \mathrm{I} \rightarrow \mathrm{J} 2 \\
\text { Berlin(railway)Hamburg(railway)Wuhan(railway) Shanghai }\end{array}$ & 831976.2 & 338.69 \\
\hline 3 & $\begin{array}{c}\mathrm{A} \rightarrow \mathrm{B} 2 \rightarrow \mathrm{G} \rightarrow \mathrm{J} 3 \\
\text { Berlin(railway)Duisburg(railway)Chongqing(waterway) Shanghai }\end{array}$ & 776988.0 & 375.07 \\
\hline 4 & $\begin{array}{c}\mathrm{A} \rightarrow \mathrm{C} 2 \rightarrow \mathrm{J} 3 \\
\text { Berlin(railway) Hamburg(waterway) Shanghai }\end{array}$ & 762248.6 & 509.43 \\
\hline
\end{tabular}

From the above table, it can be seen that the total transport cost reduces from Route 1 to Route 4, but the transport time increases. Route 1 and Route 2 are the whole land transport, wherein, Route 1 is road-rail transport and Route 2 is the whole railway transport. Compared with them, the transport cost of routes including road transport is higher rather the transport time is lower. Route 3 and Route 4 are both rail-water transport, but the difference between them is that Route 3 is water transport of Yangtze River and Route 4 is sea transport. The speed of the latter is doubled than that of the former. Besides, the route distance of water section also has a big difference. However, it also can be seen that with the increase of water distance, the transport time is longer.

We compares each pair of routes respectively in order to compare the different transport combinations more directly for the impact of total transport cost and total transport time. The comparison table of different routes is shown in Table 6. 
Table 6 Comparison table of different routes

\begin{tabular}{|c|c|c|c|c|c|}
\hline No. & Comparison on a pair of routes & \multicolumn{2}{|c|}{ Classification } & $\begin{array}{c}\text { Total transport } \\
\text { cost }\end{array}$ & $\begin{array}{c}\text { Total transport } \\
\text { time }\end{array}$ \\
\hline 1 & Route 1 and Route 2 & Benchmark item & Route 2 & Increase $80 \%$ & Reduce $13 \%$ \\
\hline 2 & Route 2 and Route 3 & Benchmark item & Route 3 & Increase $7 \%$ & Reduce $10 \%$ \\
\hline 3 & Route 1 and Route 4 & Benchmark item & Route 4 & Increase $97 \%$ & Reduce $42 \%$ \\
\hline 4 & Route 2 and Route 4 & Benchmark item & Route 4 & Increase $9 \%$ & Reduce $34 \%$ \\
\hline
\end{tabular}

From the table, it can be seen that if you want to compromise the requirements of time and cost that is the transport time and cost is both at a lower level, sea-rail transport will be the better choice.

\section{Conclusions}

In this paper, it takes container sea-rail transport as the main research object and considers that our country promote the development of container multimodal transport and The Belt and Road strategy in recent years. It chooses China and Europe as object of research and builds minimum time-cost double-objective model based on it for route optimization problem. Wherein, it takes Pareto optimal solution set into account and designs a multi-objective ant colony algorithm by MATLB programming. Finally, it is found that the combining form of sea-rail transport is superiority through instance simulation for container transport route between China and Europe.

\section{References}

[1] Reddy V R, Kasilingam R G. Intermodal transportation considering transfer costs [A]. Proceedings of the 1995 Global Trends Conference of the Academy of Business Administration[C].Aruba: 1995.

[2] Athanasios Ziliaskopoulos, Whitney Wardell. An intermodal optimum path algorithm for multi-modal networks with dynamic arc travel times and switching delays [J].European Journal of Operational Research, 2000, 125(3): 486-502

[3] Lozano A, Storehi G. Shortest viable path algorithm in multimodal networks [J].Transportation Research Part A, 2001, 35(3)

[4] Sathaporn Ooasanon, Elise D M. Multi-criteria adaptive paths in stochastic, time-varying networks [J].European Journal of Operational Research, 2006, 173:72-91

[5] Milan Janie. Modelling the full costs of an intermodal and road freight transport network [J]. Tansportation Research Part D, 2007, (12); 33-44.

[6] T.-S.Chang. Best routes selection in international intermodal networks [J]. Computers and Operations Research Archive, 2008, 35: 2877-2891.

[7] Jae Hyung Cho, Hyun Soo Kira, Hyung Rim Choi, An intermodal transport network planning algorithm using dynamic programming-A case study: from Busan to Rotterdam in intermodal freight routing [J]. Springer Science Business Media, 2010, 36(3): 529-541.

[8] H. Ayed, C. Galvez-Fernandez, Z. Habbas, D. Khadraoui. Solving time-dependent multimodal transport problems using a transfer graph model [J]. Computers \& Industrial Engineering, 2011, 61 (2): 391-401.

[9] Jian Liang, Wenming Cheng, Min Zhang. Simulation research on operation of loading and unloading in railway container center station [J].Journal of System Simulation. 2009, 21 (9):6290-6297.

[10] Minyuan Zhang. Analysis and research on handling technology and production efficiency of automated container terminal [D]. Wuhan. Wuhan University of Technology. 2014. 